Cristina Matesanz López'

Cristina Loras Gallego ${ }^{2}$

Juana Cacho Calvo ${ }^{2}$

Israel John Thuissard

Vasallo ${ }^{3}$

María Teresa Río Ramírez ${ }^{1}$

\section{Patients with non-tuberculous mycobacteria in respiratory samples: a 5-year epidemiological study}

\author{
Department of Respiratory Medicine, Hospital Universitario de Getafe, Madrid, Spain \\ ${ }^{2}$ Department of Microbiology, Hospital Universitario de Getafe, Madrid, Spain \\ ${ }^{3}$ Department of Statistic, Universidad Europea de Madrid, Madrid, Madrid, España
}

Article history

Received: 13 October 2020; Revision Requested: 8 November 2020; Revision Received: 25 November 2020; Accepted: 2 December 2020; Published: 1 February 2021

\section{ABSTRACT}

Background. This study describes the characteristics of patients with positive cultures of non-tuberculous mycobacteria (NTM) in respiratory samples and determines the risk factors that predispose for a reinfection with different NTM species.

Methods. Patients with NTM isolates in respiratory samples between 2013 and 2017 were studied. Additionally, risk factors and comorbidities of reinfected patients were analyzed.

Results. The study was focused on the 280 patients with NTM isolation (28 were reinfected with at least another species). Mycobacterium avium was the main isolated species. $68 \%$ were men. Median age was 73.2. Most remarkable risk factors were: tobacco, COPD and bronchiectasis. Bronchiectasis turned out to be a statistically significant risk factor for reinfection. Only 12 patients (12.4\%) were treated.

Conclusion. NTM were mainly identified in elderly patients. The most frequent comorbidities were COPD and smoking, whereas the most frequent species was M. avium. Previous bronchiectasis was a predisposing factor for reinfection.

Keywords: lung infections, bronchiectasis, reinfection factors

\section{Pacientes con aislamientos de micobacterias no tuberculosas en muestras respiratorias: un estudio epidemiológico de 5 años}

Introducción. Este estudio describe las caracteristicas de los pacientes con aislamientos de micobacterias no tuberculosas (MNT) en muestras respiratorias y determina los factores de riesgo que predisponen a una reinfección por diferentes especies de MNT.

Métodos. Se estudiaron pacientes con aislados de MNT en muestras respiratorias entre 2013 y 2017. Además, se analizaron los factores de riesgo y las comorbilidades de los pacientes reinfectados.

Resultados. El estudio se centró en los 280 pacientes con aislamiento de MNT (28 fueron reinfectados con al menos otra especie). Mycobacterium avium fue la principal especie aislada. El 68\% eran hombres. La edad media fue de 73,2 años. Los factores de riesgo más destacables fueron: tabaco, EPOC y bronquiectasias. Las bronquiectasias resultaron ser un factor de riesgo estadísticamente significativo de reinfección. Solo se trató a 12 pacientes (12,4\%).

Conclusión. Las MNT se identificaron principalmente en pacientes mayores. Las comorbilidades más frecuentes fueron la EPOC y el tabaquismo, mientras que la especie más frecuente fue M. avium. Las bronquiectasias previas fueron un factor predisponente para la reinfección.

Palabras clave: infecciones pulmonares, bronquiectasias, reinfección

\section{INTRODUCTION}

Non-tuberculous mycobacteria (NTM) are environmental bacteria mainly found in soils and water. In Spain there is no precise epidemiological data of NTM respiratory infection because it is not an obligatory reportable disease. This study describes the epidemiological, clinical and radiological characteristics of patients with positive cultures of NTM in respira- 
tory samples and analyzes the comorbidities and risk factors of these patients in order to determine if any of them can be considered a predisposing factor for a reinfection by two or more different species of NTM.

\section{MATERIAL AND METHODS}

Retrospective observational study. Inclusion criteria were as follows: (i) Patients with NTM isolates in respiratory samples between 2013 and 2017 (ii) Follow-up at Hospital Universitario de Getafe, Madrid (Spain), a hospital located in the south of Madrid, with a reference population of 209.720 people [1].
Specimens were processed for direct examination with the auramine-rhodamine stain method and for culture in solid (Coletsos) and liquid medium at $35-37^{\circ} \mathrm{C}$. An automatic reading system (BATECT ${ }^{\mathrm{TM}}$ MGITTM 960, Becton Dickinson, USA) was used as liquid medium. Species level identification was carried out using a reverse hibrydization and amplification test (GenoType Mycobacterium CM/AS, Hain Lifescience, Nehren, Germany).

Clinical and epidemiological data were obtained from the medical records. For each patient 12 specific risk factors were collected, including: exposure to toxic habits, respiratory comorbidities, previous treatment with systemic corticosteroids in the last 30 days, diagnosis of established liver disease,

\begin{tabular}{|c|c|c|c|c|}
\hline Table 1 & $\begin{array}{l}\text { Species isolated } \\
\text { studied. }\end{array}$ & 29 reinfected $p$ & tients during & the 5 years \\
\hline Reinfected patients & First episode & 1st reinfection & 2nd reinfection & 3rd reinfection \\
\hline Patient 1 & M. avium & M. fortuitum & M. intracellulare & - \\
\hline Patient 2 & M. avium & M. fortuitum complex & - & - \\
\hline Patient 3 & M. avium & M. gordonae & M. intracellulare & - \\
\hline Patient 4 & M. avium & M. gordonae & - & - \\
\hline Patient 5 & M. avium & M. gordonae & - & - \\
\hline Patient 6 & M. avium & M. gordonae & - & - \\
\hline Patient 7 & M. avium & M. gordonae & - & - \\
\hline Patient 8 & M. avium & M. intracellulare & - & - \\
\hline Patient 9 & M. avium & M. intracellulare & - & - \\
\hline Patient 10 & M. avium & M. mucogenicum & - & - \\
\hline Patient 11 & M. chelonae & M. abscessus & - & - \\
\hline Patient 12 & M. chelonae & M. avium & - & - \\
\hline Patient 13 & M. chelonae & M. avium & - & - \\
\hline Patient 14 & M. chelonae & M. mucogenicum & - & - \\
\hline Patient 15 & M. fortuitum & M. avium & M. lentiflavum & - \\
\hline Patient 16 & M. fortuitum & M. avium & - & - \\
\hline Patient 17 & M. fortuitum & M. avium & - & - \\
\hline Patient 18 & M. fortuitum & M. kansasi & - & - \\
\hline Patient 19 & M. fortuitum & M. lentiflavum & M. peregrinum & M. abscessus \\
\hline Patient 20 & M. fortuitum & M. lentiflavum & - & - \\
\hline Patient 21 & M. fortuitum & M. peregrinum & - & - \\
\hline Patient 22 & M. fortuitum complex & M. xenopi & - & - \\
\hline Patient 23 & M. intracellulare & M. avium & - & - \\
\hline Patient 24 & M. intracellulare & M. avium & - & - \\
\hline Patient 25 & M. intracellulare & M. peregrinum & - & - \\
\hline Patient $26^{a}$ & M. kansasii & M. fortuitum & - & - \\
\hline Patient 27 & M. lentiflavum & M. intracellulare & - & - \\
\hline Patient 28 & M. xenopi & M. intracellulare & M. avium & - \\
\hline
\end{tabular}

${ }^{\text {a }}$ nly patient who received treatment. 


\begin{tabular}{l|cc}
\hline Table 2 & $\begin{array}{l}\text { Non-tuberculous mycobacterial } \\
\text { (NTM) isolated species: frequency and } \\
\text { percentage of isolates }\end{array}$ \\
\hline NTM & N & $\%$ \\
\hline M. avium & 152 & 48.4 \\
\hline M. intracellulare & 52 & 16.6 \\
\hline M. fortuitum & 38 & 12.1 \\
\hline M. gordonae & 25 & 8 \\
\hline M. lentiflavum & 13 & 4.1 \\
\hline M. chelonae & 10 & 3.2 \\
\hline M. xenopi & 6 & 1.9 \\
\hline M. mucogenicum & 5 & 1.6 \\
\hline M. peregrinum & 5 & 1.6 \\
\hline M. kansasii & 3 & 1 \\
\hline M. abscessus & 2 & 0.6 \\
\hline M. scrofulaceum & 2 & 0.6 \\
\hline M. brumae & 1 & 0.3 \\
\hline Total & 314 & 100 \\
\hline & & \\
\hline
\end{tabular}

HIV, renal insufficiency, active malignancy in the last year and chemotherapeutic or immunosuppressive drugs at the time of diagnosis. Radiological findings were also taken into account: nodules, infiltrates, cavitation and bronchiectasis.

The ATS/IDSA guide [2] was considered to define the microbiological, radiological and microbiological criteria for infection. These were: compatible signs and symptoms without any other causes that justify it, radiological findings suggestive of NTM infection (pulmonary cavitation, infiltrates, nodules...), positive culture results from at least two separate expectorated sputum samples, positive culture results from at least one bronchial wash or lavage and lung biopsy with mycobacterial histologic features and positive culture for NTM.

The study protocol CEIm 19-19 was approved by the Ethics Committee for Drug Research of Hospital Universitario de Getafe.

Statistical analysis. The study variables are described as absolute (n) and relative (\%) frequency for qualitative variables. The mean \pm SD or the median $[R I C]$ were identified to determine the quantitative variables based on the study of their normality. To analyze the statistically significant differences based on the number of isolated species, the Chi-square test or Fisher's exact test was applied for qualitative variables. For the quantitative variables, the Student's T-test or U-Mann Whitney test was used depending on their parametric behavior. Whenever $p$-value was lower than the alpha error (5\%) it was considered that there are significant differences.

\section{RESULTS}

During the 5 years studied, a total of 396 mycobacteria were isolated in respiratory samples (82 Mycobacterium tuber- culosis complex and 314 NTM). The study was focused on the 280 patients with NTM isolation. The total of NTM isolates in these 280 patients was 314 , since 28 patients were reinfected with at least another species within the studied period. They were mainly men (62.1\%) and the median age was 74.75. Half of the patients were previously diagnosed with bronchiectasis. M. avium was the most isolated species (7/29) in the first reinfection episode. A minority of patients (12) received treatment. Half were infected with $M$. avium, 2 with $M$. intracellulare, 1 with $M$. fortuitum, 1 with $M$. kansasii, 1 with $M$. lentiflavum and 1 with M. xenopi. There was no difference by gender and the median age was 73 years, identical to that of the total sample. All of them met disease criteria by applying the ATS/ IDSA criteria [2] Table 1 shows the different species isolated in the reinfected patients.

Considering the reference population of the hospital, the cumulative incidence of patients with NTM isolation was about 13 per 10,000 people over the studied time, while the cumulative incidence of patients with tuberculosis was 39 per 100,000 . A total of 190 patients (68\%) were men while $90(32 \%)$ were women. The median age was 73.2 [96.6]. The Spanish nationality was the most common (92.1\%) followed far behind by the Moroccan (2.9\%).

The prevailing signs and symptoms were: chronic cough (43.6\%), chronic expectoration (32.1\%), constitutional syndrome (15.7\%) and hemoptysis (15\%).

Radiologically speaking, a thoracic computed tomography scan (CT) was performed in 174 (61.7\%) with the following findings: bronchiectasis $17.8 \%$, lung infiltrates $16.7 \%$, nodules $14.9 \%$, nonspecific lymphadenopathy $10.3 \%$ and cavitations $3.4 \%$. The findings in the rest of them were not suggestive of NTM infection.

Samples were: sputum 69\%, bronchial aspirate (BAS) 21\%, bronchoalveolar lavage (BAL) 9\% and pleural effusion $<1 \%$. In 129 patients the NTM was isolated in only one sputum, while in the remaining 151 patients (53.9\%) the NTM was isolated in 2 or more sputum, BAS or BAL.

The isolated species are summarized in table 2.

Analyzing the influence that different comorbidities may have on the risk of being reinfected by a second species of NTM (table 3), only bronchiectasis turned out to be a statistically significant risk factor $(p=0.008)$. OR $(95 \% \mathrm{Cl}): 3,050$ $(1,294-7,192)$.

\section{DISCUSSION}

In our 5 year-study we have not found a significant increase in NTM isolations in relation to MTC. On the one hand these findings may be due to a decrease in the incidence rate of tuberculosis in our area over the past 23 years. On the other hand, most of the exceeding number of NTM isolations were in years before the studied period. Moreover, in Spain the epidemiology of NTM infection is not well known since little data have been published $[3,4]$. 


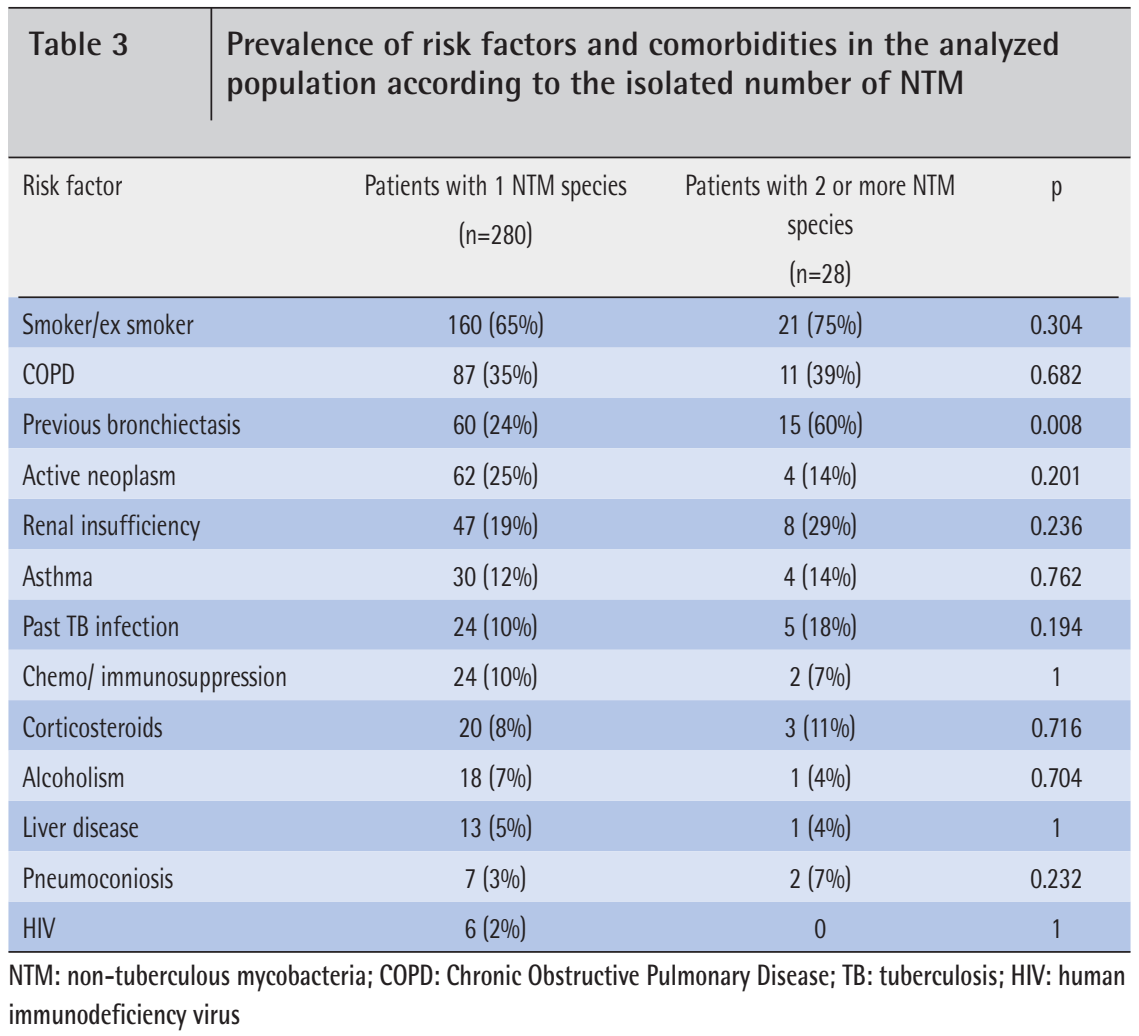

According to the data provided by the Public Health Service of the Community of Madrid, in our health area the incidence rate of $M$. tuberculosis has decreased from 41.3 cases per 100,000 inhabitants in 1994 , to 11.8 in 2017. In other study carried out by our laboratory it was found that in 1994 86.3\% of the isolated mycobacteria were $M$. tuberculosis complex while in 2013 this proportion fell to $27.4 \%$ [5]. This fact reflects the decrease in the incidence of tuberculosis in our health area. Our study shows that the percentage of these isolates has stabilized ever since while NTM isolation is increasing. Improved molecular identification of NTM may have played an important role, although it does not explain the decrease in MTC.

Considering sex and age, the number of male patients exceeded almost twice the number of women, which is consistent with what has been published in Europe to date $[6,7-9]$, although the tendency is to increase female patients.

In 2014, van der Werf et al. [10] collected data from ten European countries and described that the most frequently isolated NTM were, in descending order, M. avium, M. gordonae and $M$. xenopi. In our study, M. avium was also the most isolated species, although, M. xenopi was only isolated in a small percentage (1.9\%).

Almost half of the patients (129) had a single positive non-invasive respiratory sample (sputum), so, applying the ATS/IDSA criteria [2], these patients did not meet the microbiological criteria for respiratory disease due to NTM. The rest of the patients, corresponding to 151 (53.9\%), did comply with them.
In most cases, there is some host factor that favors NTM infection, usually the existence of previous pulmonary pathology or immunosuppression [11]. Almost all the patients in our sample had some type of comorbidity or associated risk factor. As in similar studies $[12,13]$, the most frequent comorbidity was COPD, diagnosed in 35\% of patients, mostly men.

Previous bronchiectasis (without CF), in addition to being the second most frequent risk factor in our study, was the only one found as a predisposing factor for a reinfection by another different NTM. According to our study, patients with bronchiectasis are 3 times more likely to be re-infected with 2 or more different NTM than patients without previous bronchiectasis. This reinforces the pathogenic role of bronchiectasis in this type of infections.

As other studies suggest, bronchiectasis appear to be the result of a chronic infection such as NTM pulmonary infection $[14,15]$. In turn, the destruction of bronchial structure is a predisposing factor for a NTM infection. Therefore, patients with underlying bronchiectasis and environmental exposure are predisposed to a reinfection [16]:

The use of oral corticosteroids the month prior to isolation was also analyzed. The $8 \%$ of the patients had received such treatment. To date, there is scarce data published in this topic. Although in our study only systemic corticosteroids were analyzed, two case-control studies suggest the relationship between the use of inhaled corticosteroids and the development of pulmonary disease due to NTM $[17,18]$.

From the radiological point of view, the most frequent 
finding in the thoracic CT scan was the presence of bronchiectasis $(17.8 \%)$. This is hard to interpret since bronchiectasis can be both a consequence and a cause of NTM infection. Another frequent radiological pattern was parenchymal infiltrates and nodular lesions. It agrees, therefore, with other studies where it has been seen that the association of nodular lesions and bronchiectasis is related to a greater extent to an infection by NTM compared to that produced by M. tuberculosis [19].

Another interesting data of our study is the small number of patients who received treatment. Only $12.4 \%$ of the total. There was no difference by gender and the median age was 73 years, identical to that of the total sample, which does not guide a different therapeutic approach according to age. All of them met disease criteria by applying the ATS/ IDSA criteria [2]. M. avium complex, is the most frequently described as causing respiratory disease. Taking the treated patients into account, in more than half of them the responsible agent was a NTM of the M. avium complex. The difficulty of differentiating between colonization and disease, the long duration of treatments and the side effects may be some of the reasons that justify the low rate of patients treated in our study.

Within the limitations of our study, it is worth highlighting the difficulty of interpreting medical records retrospectively. Consequently, it was not possible to make a difference between colonization and disease.

In conclusion, in our area, the most frequently isolated NTM was M. avium in elderly patients, with smoking exposure and COPD as the main comorbidity. In addition, previous bronchiectasis was a predisposing factor for reinfection.

\section{FUNDING}

None to declare

\section{CONFLICTS OF INTEREST}

The authors declare that there is no conflict of interest regarding the publication of this article.

\section{REFERENCES}

1. Consejería de sanidad. Memoria 2013, servicio madrileño de salud. 2013. Available at http://www.madrid.org/bvirtual/BVCM017701. pdf.

2. Griffith DE, Aksamit T, Brown-Elliott BA, Catanzaro A, Daley C, Gordin $F_{1}$ et al. ATS Mycobacterial Diseases Subcommittee; American Thoracic Society; Infectious Disease Society of America. An official ATS/IDSA statement: diagnosis, treatment, and prevention of nontuberculous mycobacterial diseases. Am J Respir Crit Care Med. 2007;175(4):367-416. doi: 10.1164/rccm.200604-571ST.

3. Martín-Casabona N, Bahrmand AR, Bennedsen J, Thomsen VO, Curcio M, Fauville-Dufaux et al. Spanish Group for Non-Tuberculosis Mycobacteria. Non-tuberculous mycobacteria: patterns of isola- tion. A multi-country retrospective survey. Int J Tuberc Lung Dis. 2004;8(10):1186-93. PMID: 15527150.

4. Santin M, Barrabeig I, Malchair P, Gonzalez-Luquero L, Benitez MA, Sabria J et al. Pulmonary Infections with Nontuberculous Mycobacteria, Catalonia, Spain, 1994-2014. Emerg Infect Dis. 2018;24(6):1091-1094. doi: 10.3201/eid2406.172095.

5. García Cañas A. Estudio de la evolución en el diagnóstico microbiológico de las infecciones producidas por micobacterias en un periodo de 20 años (1994-2013). Madrid: Universidad Europea Madrid; 2017. Available from: https://www.educacion.gob.es/teseo/ imprimirFicheroTesis.do?idFichero=4jkaPkw0Kuo\%3D

6. Martínez González S, Cano Cortés A, Sota Yoldi LA, García García JM, Alba Álvarez LM, Palacios Gutiérrez JJ. Non-Tuberculous Mycobacteria. An Emerging Threat? Arch Bronconeumol. 2017;53(10):554560. English, Spanish. doi: 10.1016/j.arbres.2017.02.014.

7. Mencarini J, Cresci C, Simonetti MT, Truppa C, Camiciottoli G, Frilli $\mathrm{ML}$ et al. Non-tuberculous mycobacteria: epidemiological pattern in a reference laboratory and risk factors associated with pulmonary disease. Epidemiol Infect. 2017;145(3):515-522. doi: 10.1017/ S0950268816002521.

8. Monteiro NF, Peres S, Mansinho K. Non-Tuberculous Mycobacteria: Seven-Year Experience of a Tertiary Hospital. Acta Med Port. 2019: 32(3):208-213

9. Van der Werf MJ, Ködmön C, Katalini -Jankovi V, Kummik T, Soini $\mathrm{H}$, Richter $\mathrm{E}$ et al. Inventory study of non-tuberculous mycobacteria in the European Union. BMC Infect Dis. 2014;14:62. doi: 10.1186/1471-2334-14-62..

10. Weiss $\mathrm{CH}$, Glassroth J. Pulmonary disease caused by nontuberculous mycobacteria. Expert Rev Respir Med. 2012: 6(6):597-612.

11. Bodle EE, Cunningham JA, Della-Latta P, Schluger NW, Saiman L. Epidemiology of nontuberculous mycobacteria in patients without HIV infection, New York City. Emerg Infect Dis. 2008;14(3):390-6. doi: 10.3201/eid1403.061143.

12. Zhang ZX, Cherng BPZ, Sng LH, Tan YE. Clinical and microbiological characteristics of non-tuberculous mycobacteria diseases in Singapore with a focus on pulmonary disease, 2012-2016. BMC Infect Dis. 2019;19(1):436. doi: 10.1186/s12879-019-3909-3.

13. Hojo M, likura M, Hirano S, Sugiyama H, Kobayashi N, Kudo K. Increased risk of nontuberculous mycobacterial infection in asthmatic patients using long-term inhaled corticosteroid therapy. Respirology. 2012;17(1):185-90. doi: 10.1111/j.1440-1843.2011.02076.x

14. Fujita J, Ohtsuki Y, Shigeto E, Suemitsu I, Yamadori I, Bandoh S et al. Pathological findings of bronchiectases caused by Mycobacterium avium intracellulare complex. Respir Med. 2003;97(8):933-8. doi: 10.1016/s0954-6111(03)00120-3.

15. Moore EH. Atypical mycobacterial infection in the lung: CT appearance. Radiology. 1993;187(3):777-82. doi: 10.1148/radiology.187.3.8497629

16. Wallace RJ Jr, Brown-Elliott BA, McNulty S, Philley JV, Killingley J, Wilson RW et al. Macrolide/Azalide therapy for nodular/bronchiectatic mycobacterium avium complex lung disease. Chest. 2014;146(2):276-282. doi: 10.1378/chest.13-2538.

17. Andréjak $C$, Nielsen $R$, Thomsen $V \emptyset$, Duhaut $P$, Sørensen HT, Thom- 
sen RW. Chronic respiratory disease, inhaled corticosteroids and risk of non-tuberculous mycobacteriosis. Thorax. 2013;68(3):256-62. doi: 10.1136/thoraxjnl-2012-201772

18. Kwak N, Lee CH, Lee HJ, Kang YA, Lee JH, Han SK et al. Non-tuberculous mycobacterial lung disease: diagnosis based on computed tomography of the chest. Eur Radiol. 2016;26(12):4449-4456. doi: 10.1007/s00330-016-4286-6.

19. Primack SL, Logan PM, Hartman TE, Lee KS, Müller NL. Pulmonary tuberculosis and Mycobacterium avium-intracellulare: a comparison of CT findings. Radiology. 1995;194(2):413-7. doi: 10.1148/ radiology.194.2.7824720. 